\title{
Analisis Semiotika Roland Barthes Pada Masjid Keraton Buton di Kota Baubau, Sulawesi Tenggara
}

\author{
Nurul Fitriana Bahri* \\ 1Program Magister Desain, Fakultas Seni Rupa dan Desain, Institut Teknologi Bandung, \\ Bandung, Indonesia
}

\begin{abstract}
Baubau is one of the cities that has a lot of potential in local culture, located within Southeast Sulawesi Province of Buton Island. Fort of Keraton Buton is one of the local cultures that has become Baubau's identity as well as proudly icon of its people and Southeast Sulawesi in general. Inside of the fort's complex stands a mosque that is a legacy from Buton Sultanate. This mosque is known as Masjid Keraton Buton. Masjid Keraton Buton is an architectural work that has become the united source of ideas from every social field, including how religion belief was interpreted and understood for the people's interest. It's difficult to divide its architectural presence to two form of culture that precedes its birth. One is social system and the other is idea complexity. Roland Barthes semiotic analysis of shape, construction, space and color on Masjid Keraton Buton is conducted in this essay. Semiotic is a knowledge that learns about signs, how it is functioned and the meaning it's produced. Roland Bathes is one of the figures of semiotic, he argued semiotic is part of the linguistic. According to him, language is a sign system that reflects assumptions from one certain community in a certain time. This matter revealed an idea and is an element that shaped from signs and included inside a structure.
\end{abstract}

Keywords: mosque, keraton, Buton, semiotic, Roland Barthes

$\begin{array}{ll}\text { Nurul Fitriana Bahri } \\ \text { Email } & \text { : nurulfitrianabahri@gmail.com } \\ \text { Address } & : \text { Program Magister Desain, Fakultas Seni Rupa dan Desain } \\ & \text { Institut Teknologi Bandung } \\ & \text { Jalan Ganesha no. } 10 \text { Bandung }\end{array}$




\section{Analisis Semiotika Roland Barthes Pada Masjid Keraton Buton di Kota Baubau, Sulawesi Tenggara}

Nurul Fitriana Bahri

\section{SEMIOTIKA ROLAND BARTHES}

Semiotika berasal dari kata Yunani: semeion, yang berarti tanda. Penjelajahan semiotika sebagai metode kajian kedalam pelbagai cabang keilmuan dimungkinkan karena ada kecenderungan untuk memandang pelbagai wacana sosial sebagai fenomena bagasa. Dengan kata lain, bahasa dapat dijadikan dasar dalam beragam wacana sosial. Berdasarkan pandangan semiotika, bila seluruh praktik sosial dapat dianggap sebagai fenomena bahasa, maka semuanya dapat juga dipandang sebagai tanda. Hal ini dimungkinkan karena luasnya pengertian tanda itu sendiri [1].

Semiotika adalah suatu ilmu atau metode analisis yang digunakan untuk mengkaji tanda. Semiotika, pada dasarnya hendak mempelajari bagaimana kemanusiaan (humanity) memaknai hal-hal (things). Memaknai (to signify) dalam hal ini tidak dapat dicampuradukkan dengan mengkomunikasikan (to communicate). Semiotika adalah suatu disiplin yang menyelidiki semua bentuk komunikasi yang terjadi dengan sarana signs 'tanda-tanda' dan berdasarkan pada sign system (sistem tanda) [2].

Dapat dikatakan pula semiotika merupakan ilmu yang mempelajari tentang tanda, berfungsinya tanda, dan produksi makna. Tanda merupakan sesuatu yang bagi seseorang berarti sesuatu yang lain. "Segala sesuatu yang dapat diamati atau dibuat teramati dapat disebut tanda. Karena itu, tanda tidaklah terbatas pada benda. Adanya peristiwa, tidak adanya peristiwa, struktur yang ditemukan dalam sesuatu, suatu kebiasaan, semua ini dapat disebut tanda" [3].

Roland Barthes merupakan salah satu tokoh semiotika. la berpendapat bahwa semiotika merupakan bagian dari linguistik. Menurutnya, bahasa adalah sebuah sistem tanda yang mencerminkan asumsi-asumsi dari suatu masyarakat tertentu dalam waktu tertentu. Hal ini mengungkapkan suatu gagasan (yang bermakna) dan merupakan unsur yang terbentuk dari penanda-petanda, dan terdapat dalam sebuah struktur.

Salah satu area penting yang dirambah Barthes dalam studinya tentang tanda adalah peran pembaca (the reader). Konotasi, walaupun merupakan sifat asli tanda, membutuhkan keaktifan pembaca agar dapat berfungsi. Barthes secara panjang lebar mengulas apa yang sering disebut sebagai sistem pemaknaan tataran kedua, yang dibangun di atas sistem lain yang telah ada sebelumnya. Sastra merupakan contoh paling jelas sistem pemaknaan tataran kedua yang dibangun di atas bahasa sebagai sistem yang pertama. Sistem kedua ini oleh Barthes disebut dengan konotatif, yang dibedakan dari denotatif atau sistem pemaknaan tataran pertama. 


\begin{tabular}{|c|c|c|c|}
\hline & $\begin{array}{l}\text { signifier } \\
\text { (penanda) }\end{array}$ & $\begin{array}{ll}\text { 2. } & \text { signified } \\
\text { (petanda) }\end{array}$ & \\
\hline \multicolumn{4}{|c|}{ 3. denotative sign (tanda denotatif) } \\
\hline \multicolumn{3}{|c|}{$\begin{array}{l}\text { 4. CONNOTATIVE SIGNIFIER } \\
\text { (PENANDA KONOTATIF) }\end{array}$} & $\begin{array}{l}\text { 5. CONNOTATIVE SIGNIFIED } \\
\text { (PETANDA KONOTATIF) }\end{array}$ \\
\hline \multicolumn{4}{|c|}{ 6. connotative sign (tanda konotatif) } \\
\hline
\end{tabular}

Gambar 1 Peta Tanda Roland Barthes

Dari peta Barthes di atas terlihat bahwa tanda denotatif terdiri atas penanda dan petanda. Akan tetapi, pada saat bersamaan, tanda denotatif adalah juga penanda konotatif. Jadi, dalam konsep Barthes, tanda konotatif tidak sekadar memiliki makna tambahan, namun juga mengandung kedua bagian tanda denotatif yang melandasi keberadaannya [2].

Dalam bahasa (language), dibalik makna 'literal' (denotasi), kata-kata tertentu dapat memiliki konotasi. Dalam semiotika, denotasi dan konotasi adalah istilah-istilah yang menjelaskan antara signifier (penanda) dengan signified-nya (petanda). Makna denotatif suatu kata ialah makna yang biasa ditemukan dalam kamus. Denotasi cenderung digambarkan sebagai makna yang definitional, literal (harfiah), jelas, atau commonsense dari sebuah tanda. Makna konotatif ialah makna denotatif ditambah dengan segala gambaran, ingatan, dan perasaan yang ditimbulkan. Konotasi mengarah kepada maknamakna kultural yang terpisah/berbeda dengan kata dan bentuk-bentuk lain dari komunikasi [2].

Di dalam semiotika Barthes, denotasi merupakan sistem signifikasi tingkat pertama, sementara konotasi merupakan tingkat kedua. Tanda lebih terbuka untuk beragam interpretasi dalam bentuk konotasi daripada denotasi. Dalam hal ini, denotasi justru lebih diasosiasi dengan ketertutupan makna. Sebagai reaksi untuk melawan keharfiahan denotasi, Barthes mencoba menyingkirkan dan menolaknya. Baginya yang ada hanyalah konotasi. la lebih lanjut mengatakan bahwa makna "harfiah" merupakan sesuatu yang bersifat alami yang dikenal dengan teori signifikasi.

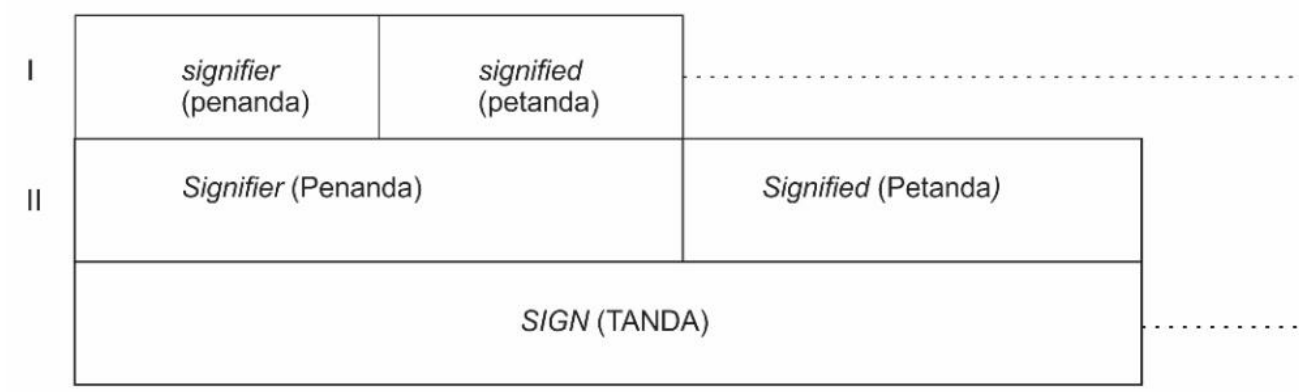

Denotation/Denotasi (Makna Primer)

Connotation/Konotasi (Makna Sekunder)

Gambar 2 Bagan Tingkatan Makna Roland Barthes

Berdasarkan bagan di atas, pemaknaan terjadi dalam dua tahap. Tanda (penanda dan petanda) pada tahap pertama dan menyatu, sehingga dapat membentuk penanda pada tahap kedua. Kemudian pada tahap berikutnya penanda dan petanda yang telah menyatu ini dapat membentuk petanda baru yang merupakan perluasan makna. 
Dengan demikian, semiologi Barthes tersusun atas tingkatan-tingkatan sistem bahasa dalam dua tingkatan bahasa. Bahasa pada tingkat pertama adalah bahasa sebagai objek dan bahasa tingkat kedua yang disebutnya sebagai metabahasa. Bahasa ini merupakan suatu sistem tanda yang berisi penanda dan petanda. Sistem tanda kedua terbangun dengan menjadikan penanda dan petanda tingkat pertama sebagai petanda baru yang kemudian memiliki penanda baru sendiri dalam suatu sistem tanda baru pada taraf yang lebih tinggi. Sistem tanda pertama disebutnya dengan istilah denotasi atau sistem terminologis, sedang sistem tanda tingkat kedua disebutnya sebagai konotasi atau sistem retoris atau mitologi. Konotasi dan metabahasa adalah cermin yang berlawanan satu sama lain. Metabahasa adalah operasi-operasi yang membentuk mayoritas bahasabahasa ilmiah yang berperan untuk menerapkan sistem riil, dan dipahami sebagai petanda, di luar kesatuan penanda-penanda asli, di luar alam deskriptif. Sementara itu, konotasi meliputi bahasa-bahasa yang utamanya bersifat sosial dalam hal pesan literal memberi dukungan bagi makna kedua dari sebuah tatanan artifisial atau ideologis secara umum

\section{ANALISA SEMIOTIKA ROLAND BARTHES PADA MASJID KERATON BUTON}

Baubau adalah salah satu kota yang terletak di Pulau Buton, Provinsi Sulawesi Tenggara yang memiliki begitu banyak potensi kearifan lokal. Salah satunya adalah benteng Keraton Buton yang telah menjadi ciri khas Kota Baubau sekaligus ikon kebanggan masyarakat Buton dan Sulawesi Tenggara. Di dalam kompleks Keraton Buton, berdiri sebuah masjid peninggalan masa Kesultanan Buton. Masjid ini dikenal dengan nama Masjid Keraton Buton. Masjid tua ini merupakan aset yang selain bernilai sejarah, juga bernilai strategis dalam konteks pengembangan syi'ar Islam. Dari arsitektur masjid, misalnya, akan memberikan gambaran tentang pola pikir masyarakat Islam dari masa ke masa. Selain itu, bangunan masjid tua ini merupakan produk budaya yang tak ternilai harganya. Warisan budaya tersebut adalah ekspresi peradaban nenek moyang bangsa yang sejatinya merupakan akar dari peradaban zaman terkini. Karena itu, penting untuk menelusuri warisan budaya tersebut untuk dipelajari dan dilestarikan sebagai kebanggaan jati diri bangsa dan sebagai bukti bahwa Indonesia lahir dari bangsa yang besar dan bermartabat [4].

Masjid ini bisa dibilang merupakan bangunan bersejarah paling terkenal di Sulawesi Tenggara setelah benteng Keraton Buton. Masjid ini dibangun pada tahun 1712 sebagai lambang kejayaan Islam di Buton pada masa itu. Tujuan pembangunannya adalah untuk tempat ibadah dan sebagai pusat penyebaran Islam di Pulau Buton. Fungsi lain dari masjid ini adalah sebagai tempat melaksanakan tradisi keagamaan khas suku Buton. Tradisi itu adalah pelaksanaan haroa untuk merayakan Maulid Nabi serta Idulfitri dan Iduladha. Hal tersebut merupakan fenomena yang menunjukkan bahwa penciptaan unsur-unsur arsitektur bangunan Masjid Keraton Buton memiliki keunikan. Terutama jika membahas tentang estetika unsur-unsur arsitektur bangunan Masjid Keraton Buton, baik yang terkait dengan unsur seni rupa dan estetika yang melandasi penciptaannya.

Masjid merupakan bangunan yang paling khas sebagai simbol Islam dan juga sebagai produk budaya masyarakat Indonesia yang heterogen. Sehingga masjid di Indoneisa tampak berbeda dengan masjid-masjid serupa yang berada di wilayah Timur Tengah: atap masjid-masjid kuno di Indonesia tidaklah mengambil bentuk kubah, tapi mengambil bentuk atap tumpang, bahkan ada yang bertingkat seperti dua tingkat. Selain sebagai tempat ibadah sholat lima waktu dan ibadah sosial lainnya, Masjid Keraton Buton juga merupakan karya arsitektur yang menjadi muara penyatuan gagasan dari berbagai bidang kemasyarakatan, termasuk bagaimana pesan keyakinan keagamaan ditafsirkan dan dipahami bagi kepentingan masyarakat. Keberadaan arsitekturnya sulit dipisahkan dua wujud kebudayaan yang mendahului kelahirannya, yaitu sistem kemasyarakatan dan kompleksitas ide. Dengan demikian, pada masjid tua tersebut telah ada asimilasi yang menghasilkan akulturasi yang harmonis dan serasi. 
Sistem tanda dalam arsitektur meliputi banyak aspek seperti bentuk fisik, bagianbagiannya, ukuran, proporsi, jarak antar bagian, bahan, warna, dan sebagainya. Sebagai suatu sistem tanda, semuanya dapat diinterpretasikan. Semua benda pakai dapat menjadi sumber informasi atau makna konvensional yaitu mengenai fungsi dari benda tersebut. Begitu juga dengan benda-benda arsitektural, secara umum dapat dikatakan bahwa bangunan memiliki makna denotatif sebagai tempat hunian. Namun, hal ini bukan berarti bangunan tidak memiliki makna konotatif.

Pembahasan estetika unsur-unsur arsitektur bangunan Masjid Keraton Buton dimulai dari melihat bentuk dan struktur unsur-unsur arsitektur bangunan Masjid Keraton. Karya arsitektur dan interior sebagai wujud budaya, tidak hanya menjawab berbagai persoalan fungsi. Manifestasi fisiknya mengakomodir aktivitas manusia. Pengaturan dan penataan bentuk dan ruang akan menentukan bagaimana arsitektur mungkin mengangkat suatu usaha, membangkitkan respons-respons, dan mengkomunikasikan makna. Bentuk dan ruang ditampilkan bukan sebagai akhir dari suatu makna, namun sebagai alat untuk memecahkan masalah dalam usaha merespons kondisi, fungsi, dan tujuan sesuai konteksnya [5].

Bentuk adalah hal pertama yang dapat dilihat oleh pengamat karena di dalamnya terdapat unsur-unsur elemen visual seperti garis, shape, value, tekstur, warna dan ruang. Bentuk dianggap sebagai suatu yang fundamental, berdiri sendiri sebagai suatu elemen tertutup dan terstruktur dalam dunia visual. Istilah organisasi, kejelasan, kebenaran dan ekspresi dalam estetika tidak selalu sama dalam aplikasinya, tetapi pada umumnya membantu dalam menggambarkan suatu kesatuan bentuk yang berhasil [5]. Struktur dan posisi ruang menentukan aktivitas manusia di dalamnya. Ruang dapat dirasakan oleh manusia dan dapat ditangkap melalui panca indera sebagai tanggapan tentang fisiknya, dan dapat dirasakan pula seperti perasaan nyaman dan aman, sehingga ruang juga dirasakan secara psikis. Secara fisik, ruang dirasakan sebagai ruang tampak atau nyata, yang memiliki jalur hubungan atau sirkulasi, pembatas ruang, tata letak atau organisasi ruang, batas tetorial atau zona, memiliki panjang dan lebar, sedangkan ruang secara psikis mampu membuat persepsi pada manusia untuk menanggapi kondisi ruang yang ditempati [5]. Dari makna unsur-unsur arsitektur bangunan terdapat nilai filosofis dan kearifan lokal yang dapat diambil yaitu nilai keyakinan, nilai sosial, dan nilai estetika.
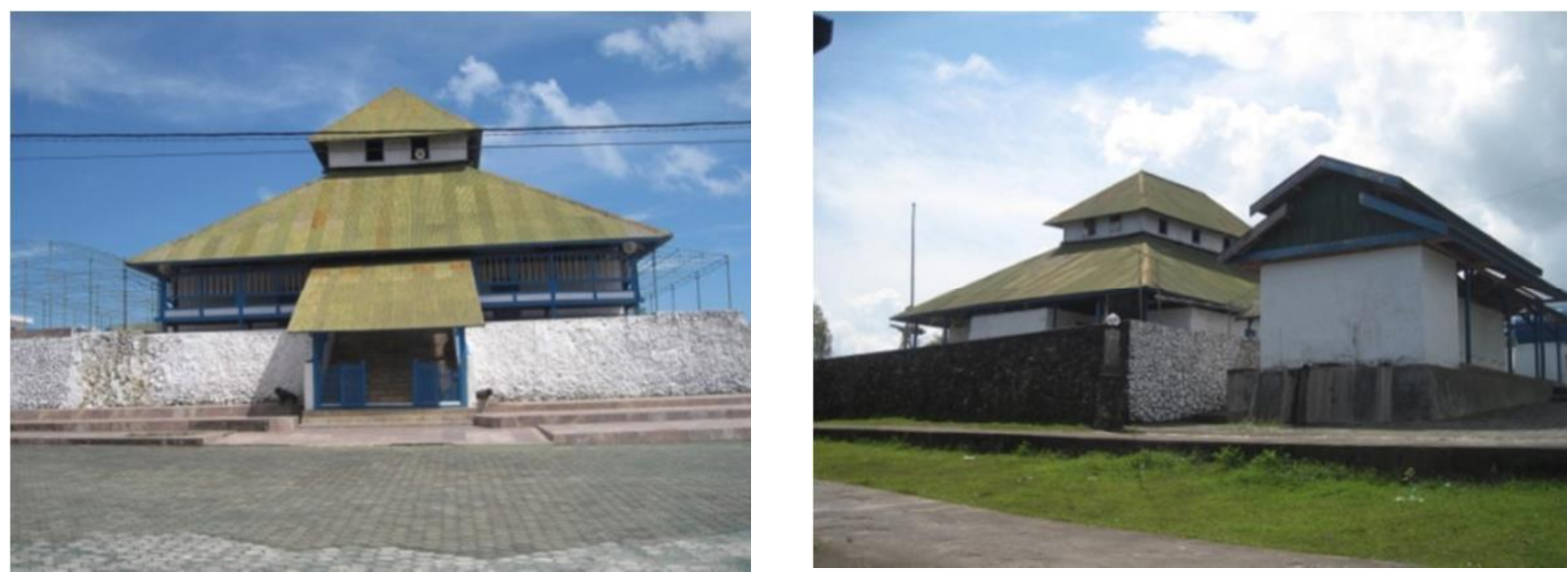

\section{Gambar 3 Masjid Keraton Buton}

Secara umum, bentuk ruang Masjid Keraton Buton adalah persegi dengan banyak tiang penyangga tanpa memiliki sekat berupa dinding pemisah. Ruang sholat antara lakilaki dan perempuan dipisahkan oleh tirai. Hal tersebut memberikan makna kesederhanaan duniawi, namun tetap menerapkan prinsip bahwa tidak ada campur-baur antara laki-laki dan perempuan, terutama saat melakukan ibadah. 
Secara keseluruhan, terdapat 60 buah tiang pada Masjid Keraton Buton; 20 buah tiang berada di ruang utama yang menjadi penyanggah lantai dua dan atap, 10 buah tiang sokoguru yang langsung ke limas kedua, selebihnya tiang berada pada sekeliling tembok (tertanam dalam tembok dinding). Makna tiang dengan jumlah dua puluh yang terdapat di ruang utama bangunan masjid ini melambangkan dua puluh sifat wajib Allah SWT.

Bentuk dan konstruksi atap berjumlah dua lapis dan berbentuk limas dengan bagian atas yang lebih kecil dan merupakan puncak yang mengerucut dari keseluruhan Masjid Keraton Buton. Susunan atap dengan puncak tersebut merupakan tanda atau denotasi yang dikonotasikan puncak dari kekuatan Sang Maha Pencipta. Bentuk atap ini diambil dari arsitektur rumah orang Buton yang dimodifikasi sedemikian rupa untuk menjadi sebuah masjid.

Masjid ini terdiri atas tiga lantai, yakni lantai pertama untuk ibadah sholat jamaah dan Jumat, lantai dua yang terbagi atas dua bagian (kanan/utara dan kiri/selatan). Lantai dua bagian utara berlantai kayu yang disanggah oleh balok, dan lantai dua sebelah selatan hanya balok tanpa lantai papan (kosong). Lantai dua diperuntukkan untuk menampung jama'ah di hari Jumat bila lantai satu penuh. Adapun lantai tiga tidak ditempati dan orang yang tidak berkepentingan tidak diperkenankan untuk naik ke lantai ini. Lantai merupakan bagian dasar dari sebuah bangunan. Lantai di Masjid Keraton Buton memiliki ketinggian yang berbeda-beda. Tingkatan tersebut dimaknai dari bawah ke atas. Hal ini memiliki makna bahwa tingkatan tersebut dimaknai dari rendah ke tinggi, dari profan ke sakral. Semakin tinggi tempat, semakin tinggi tingkat kesakralan.

Di bagian depan atau timur masjid terdapat serambi. Serambi timur bagian utara diperuntukkan bagi perangkat masjid, dan serambi timur bagian selatan diperuntukkan bagi aparat kesultanan. Hal ini menunjukkan makna tingkatan atau status hubungan sosial dalam bermasyarakat.
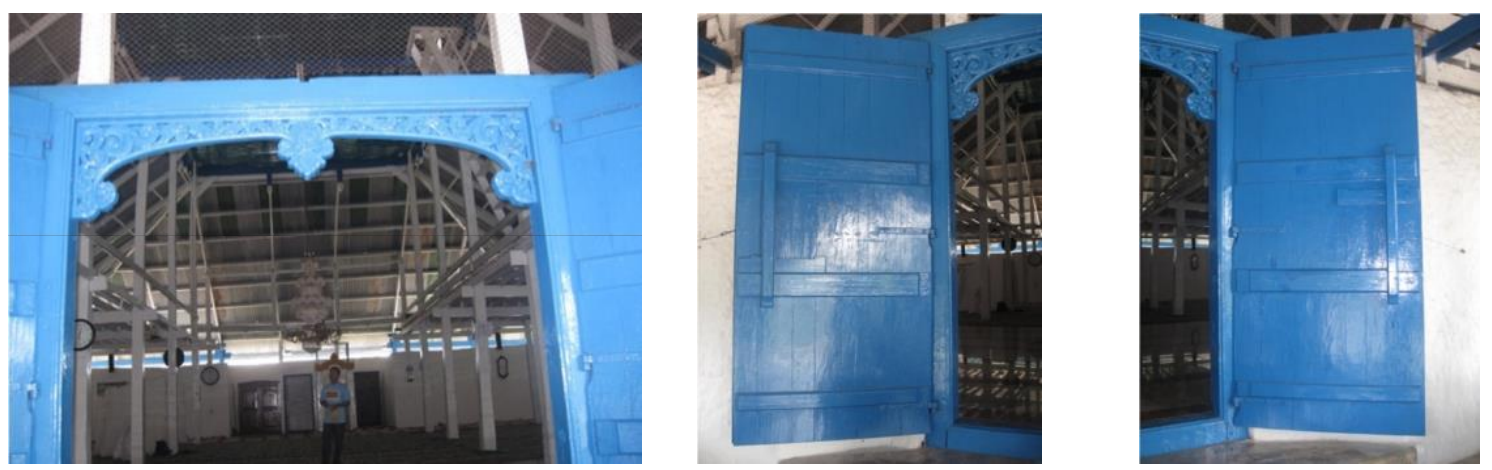

Gambar 4 Pintu Masjid Keraton Buton

Secara garis besar, warna yang dominan dalam bangunan masjid adalah warna biru muda dan putih. Warna biru muda merupakan tanda-tanda atau denotasi yang dikonotasikan sebagai warna khas keraton. Sedangkan warna putih memiliki makna bersih dan suci, sebagaimana orang-orang yang memasuki masjid tersebut dalam keadaan bersih dan suci.

Desain unsur-unsur bangunan berupa pintu, jendela, tangga lantai dilihat sebagai penandaan ikon dari situasi keagamaan pada waktu pendirian masjid. Bangunan ini memiliki 12 pintu masuk yang melambangkan jumlah lubang yang ada di tubuh manusia.

Kayu yang digunakan untuk membangun masjid ini ada 313 potong. Jumlah ini sama dengan jumlah tulang yang ada pada tubuh manusia. Jumlah anak tangga untuk masuk ke dalam masjid ada 19 buah. Jumlah ini sama dengan jumlah rakaat sholat lima waktu dalam sehari ditambah 2 rakaat sholat tahiyatul masjid. Beduk masjid memiliki panjang $99 \mathrm{~cm}$. Angka ini menandakan jumlah asmaul husna (nama-nama Allah). Diameter beduk adalah 
$50 \mathrm{~cm}$, menandakan jumlah rakaat sholat yang pertama kali diterima Rasulullah Muhammad. Tiang pasak untuk mengencangkan beduk berjumlah 33 potong, menandakan jumlah bacaan tasbih 33 kali.

Tabel 1 Analisis Semiotika Roland Barthes pada Unsur-unsur Arsitektur Bangunan Masjid Keraton Buton.

\begin{tabular}{|c|c|c|}
\hline Objek & Denotasi & Konotasi \\
\hline \multirow[b]{2}{*}{$\begin{array}{l}\text { Bentuk dan Penataan } \\
\text { Ruang }\end{array}$} & Persegi tanpa sekat & Kesederhanaan duniawi \\
\hline & Terdapat tirai di ruang utama & $\begin{array}{l}\text { Ada jarak antara laki-laki dan perempuan, } \\
\text { tidak ada campur-baur, terutama saat } \\
\text { melakukan ibadah }\end{array}$ \\
\hline \multirow{3}{*}{ Konstruksi Tiang } & Berbentuk balok & \multirow[b]{2}{*}{$\begin{array}{l}\text { Makna tiang dengan jumlah dua puluh yang } \\
\text { terdapat di ruang utama bangunan masjid } \\
\text { ini melambangkan dua puluh sifat wajib } \\
\text { Allah SWT }\end{array}$} \\
\hline & $\begin{array}{l}\text { Tiang berjumlah } 60 ; 20 \text { di ruang utama, } \\
10 \text { tiang sokoguru, selebihnya berada } \\
\text { pada sekeliling masjid }\end{array}$ & \\
\hline & $\begin{array}{l}\text { Diletakkan vertikal ke atas, sebagai } \\
\text { penyangga }\end{array}$ & $\begin{array}{l}\text { Menunjukkan hubungan manusia dengan } \\
\text { Allah SWT }\end{array}$ \\
\hline \multirow[b]{2}{*}{ Konstruksi Atap } & Berbentuk limas & \multirow[b]{2}{*}{$\begin{array}{l}\text { Menunjukkan puncak dari kekuatan Sang } \\
\text { Maha Pencipta }\end{array}$} \\
\hline & $\begin{array}{l}\text { Terdiri atas dua lapis dengan bagian } \\
\text { atas yang lebih kecil }\end{array}$ & \\
\hline \multirow{5}{*}{ Konstruksi Lantai } & Terdiri dari tiga lantai & \multirow{5}{*}{$\begin{array}{l}\text { Dengan ketinggian yang berbeda-beda, } \\
\text { tingkatan dapat dimaknai dari bawah ke } \\
\text { atas. Hal ini memiliki makna bahwa } \\
\text { tingkatan tersebut dimaknai dari rendah ke } \\
\text { tinggi, dari profan ke sakral. Semakin tinggi } \\
\text { tempat, semakin tinggi tingkat kesakralan. }\end{array}$} \\
\hline & $\begin{array}{l}\text { Lantai pertama sebagai tempat ibadah } \\
\text { sholat Jum'at }\end{array}$ & \\
\hline & $\begin{array}{l}\text { Lantai dua sebelah utara disanggah } \\
\text { oleh balok }\end{array}$ & \\
\hline & $\begin{array}{l}\text { Lantai dua sebelah selatan hanya balok } \\
\text { tanpa lantai papan }\end{array}$ & \\
\hline & $\begin{array}{l}\text { Lantai tiga hanya untuk yang } \\
\text { berkepentingan }\end{array}$ & \\
\hline \multirow{4}{*}{ Ruang Serambi } & Terletak di bagian depan/timur masjid & \multirow{4}{*}{$\begin{array}{l}\text { Hal ini menunjukkan makna tingkatan atau } \\
\text { status hubungan sosial dalam } \\
\text { bermasyarakat. }\end{array}$} \\
\hline & $\begin{array}{l}\text { Serambi timur bagian utara } \\
\text { diperuntukkan bagi perangkat masjid }\end{array}$ & \\
\hline & $\begin{array}{l}\text { Serambi timur bagian selatan } \\
\text { diperuntukkan bagi aparat kesultanan }\end{array}$ & \\
\hline & Sebagai tempat istirahat & \\
\hline \multirow{4}{*}{ Pintu } & Bentuk persegi & Kesederhanaan duniawi \\
\hline & Berwarna biru muda & $\begin{array}{l}\text { Elemen tak terpisahkan dari keraton karena } \\
\text { biru muda warna khas Keraton }\end{array}$ \\
\hline & $\begin{array}{l}\text { Di pintu utama terdapat ukiran bunga } \\
\text { nenas dengan tulisan Arab pada bagian } \\
\text { tengahnya }\end{array}$ & $\begin{array}{l}\text { Menunjukkan tahun didirikannya Masjid } \\
\text { Keraton Buton }\end{array}$ \\
\hline & Terdiri atas 12 pintu & $\begin{array}{l}\text { Melambangkan jumlah lubang yang ada di } \\
\text { tubuh manusia }\end{array}$ \\
\hline Material & $\begin{array}{l}\text { Kayu yang digunakan untuk } \\
\text { membangun masjid ada } 313 \text { potong }\end{array}$ & $\begin{array}{l}\text { Sama dengan jumlah tulang yang ada pada } \\
\text { tubuh manusia }\end{array}$ \\
\hline Tangga & $\begin{array}{l}\text { Jumlah anak tangga untuk masuk ke } \\
\text { dalam masjid ada } 19 \text { buah }\end{array}$ & $\begin{array}{l}\text { Menandakan jumlah rakaat sholat lima } \\
\text { waktu dalam sehari ditambah } 2 \text { rakaat } \\
\text { sholat tahiyatul masjid }\end{array}$ \\
\hline \multirow{3}{*}{ Beduk } & Panjang 99 centimeter & $\begin{array}{l}\text { Angka ini menandakan jumlah asmaul } \\
\text { husna (nama-nama Allah) }\end{array}$ \\
\hline & Diameter 50 centimeter & $\begin{array}{l}\text { Menandakan jumlah rakaat sholat yang } \\
\text { pertama kali diterima Rasulullah } \\
\text { Muhammad }\end{array}$ \\
\hline & $\begin{array}{l}\text { Tiang pasak untuk mengencangkan } \\
\text { beduk berjumlah } 33 \text { potong }\end{array}$ & Menandakan jumlah bacaan tasbih 33 kali \\
\hline
\end{tabular}




\section{KESIMPULAN}

Unsur arsitektur bangunan Masjid Keraton Buton memiliki nilai yang dapat diambil dari maknanya, terutama nilai religius. Religi mengandung segala keyakinan bayangan manusia tentang sifat-sifat Tuhan, tentang alam ghaib, tentang segala nilai, norma dan ajaran religi yang bersangkutan [5].

Nilai kebenaran dapat diambil dari keberadaan Masjid Keraton Buton sebagai tempat peribadahan agama Islam. Masjid adalah tampatnya umat manusia yang beragama Islam menyembah Allah SWT karena masjid dianggap sebagai rumah Allah SWT. Nilai estetika dapat dilihat dari bentuk dan struktur unsur-unsur arsitektur bangunan Masjid Keraton Buton yaitu pengadaan dan penataan setiap unsur-unsur yang terdapat di dalam masjid.

\section{DAFTAR PUSTAKA}

[1]. Piliang YA. 1998. Sebuah Dunia yang Dilipat : Realitas Kebudayaan Menjelang Milenium Ketiga dan Matinya Posmodernisme. Bandung. Mizan;

[2]. Sobur A. 2003. Semiotika Komunikasi. Bandung. Remaja Rosdakarya;

[3]. Piliang YA. 1999. Hiper-realitas Kebudayaan: Semiotika, Estetika, Posmodernisme. Jakarta. LKIS;

[4]. Idham. 2012. Pesona Masigi Ogena (Masjid Agung) Keraton Wolio Kesultanan Buton. Lektur Keagamaan Puslitbang Lektur Keagamaan Badan Litbang dan Diklat Departemen Agama RI. 10(1):209-32.

[5]. Yunianti E. 2015. Estetika Unsur-Unsur Arsitektur Bangunan Masjid Agung Surakarta. Catharsis. 4(1):15-23. 